\title{
Ticari Hibrit Çeltik Islahında Erkek Kısırlık Araştırmaları
}

\author{
*Rasim ÜNAN Halil SÜREK Recep KAYA \\ Trakya Tarımsal Araştırma Enstitüsü, Edirne \\ *Sorumlu yazar e-posta (Corresponding author; e-mail): rasimunan@hotmail.com
}

\begin{abstract}
Öz
Ticari hibrit çeltik ülkemizin için yeni bir kavram olmasına karşın dünyada 1975 yılından beri başarılı bir şekilde kullanıımaktadır. Hibrit çeltik ıslahında ilk aşama ana bitkilerde erkek kısırlık sağlamaktır. Erkek kısırık için genetik ve genetik olmayan mekanizmalardan yararlanılmaktadır. Bu çalışmanın amacı kimyasal erkek kısırlık (gametosit, CHA, genetik olmayan kısırlık); termogenik erkek kısırlık (TGMS, genetik kısırlık) ve stoplazmik erkek kısırlıktan (CMS, genetik kısırlık) yararlanılarak yerli hibrit çeşit geliştirme olanağının araştırılmasıdır. Bu deneme Edirne ekolojik koşullarında 2013-2014 yıllarında iki yıl yürütülmüştür. Kimyasal kısırlık oluşturmak üzere Paşalı, Halilbey ve Osmancık-97 çeşitlerine sapa kalkma döneminde 1000'er ppm Salisilik Asit (SA), Giberallik Asit (GA3) ve Ethephon (Ethrel) hormonları gametosit olarak uygulanmıştır. Kullanılan çeşitlerde \%22-49 arasında erkek kısırlık tespit edilmiştir. Termogenik erkek kısırlık yönteminde TGMS1 ve TGMS2 genotipleri arazi şartlarında denenmiş ve \%89-96 arasında erkek kısırlık tespit edilmiştir. Stoplazmik erkek kısırlık yönteminde ise yapılan ölçümler sonucunda V20A, 15A ve 31A CMS çeşitleri \%100 kısır olarak tespit edilmiştir. Trakya bölgesinde TGMS sistemi ve uygulan dozlardaki gametositler ticari hibrit geliştirmek için yeterli düzeyde erkek kısırlık oluşturmazken; CMS sistemi \%100 kısırlık sağlayan en uygun metot olarak tespit edilmiştir. CMS çeltikler kullanarak ana, baba ve restorer hatlardan oluşan üç hatlı metotla ticari hibrit çeşitlerin geliştirilmesi mümkün görülmektedir.
\end{abstract}

Anahtar Kelimeler: CMS, erkek kısırlık, gametosit, hibrit çeltik, TGMS

\section{Research on Male Sterility to Commercial Hybrid Rice}

\begin{abstract}
Commercial hybrid rice has been utilized effectively around the world since 1975 but it is a new concept for Turkey. First step is to provide the male sterile lines to hybrid breeding system. Genetic and non-genetic mechanisms are available to exploit for male sterility. The aim of this study is identification of utilization of male sterility systems which Chemical Male Sterility (CHA), Thermogenic Genetic Male Sterility (TGMS) and Cytoplasmic Male Sterility for Turkey Ecosystem. This experiment were conducted two years in Edirne ecological conditions in 2013-2014. Chemical Hybridisation Agents (CHA) which salicylic acid, gibberellic acid, Ethephon were sprayed as a gametocide doses $1000 \mathrm{ppm}$ at the booting stage on rice varieties which Paşalı, Halilbey, Osmancık-97. Male sterility was identified $22-49 \%$ after applied gametocide in cultivars. TGMS1 and TGMS2 cultivars have 89-96\% male sterility in the uncontrolled field situation. CMS lines which V20A, 15A, 31A have been determined 100\% male sterility. As a result, TGMS lines and applied doses gametocides are not efficient for male sterility but CMS system is efficient $100 \%$ in Trakya region. Japonica type commercial hybrid rice breeding appear possible in Turkey ecological condition using A, B and Restorer Lines.
\end{abstract}

Keywords: CMS, male sterility, gametocide, hybrid rice, TGMS

\section{Giriş}

A sya kıtası dünya çeltiğinin \%90'ını üretmektedir. Son 40 yılda çeltik üreticisi ülkeler Yeşil Devrim (Green Revolution) sayesinde pirinç ihtiyaçlarını karşılamışlardır. Fakat gelecekte büyük sıkıntılar oluşacaktır. 2030 yılına gelindiğinde dünya nüfusunu beslemek için 2000 yılına oranla \%70 daha fazla çeltik üretilmesi gerekmektedir. Bu üretim artışı daha az toprak, daha az su, daha az işçi ile yapılacaktır. Çeltik verim potansiyelini artırmak bunun için en önemli stratejilerden biridir (Rothschild 1998). Çin'de 1976'dan 1995 yılına kadar üretim 129 milyon tondan 200 milyon tona çıkarılmıştır. Bu artışın 
nedenlerinden biride hibrit çeltiklerdir. $500 \mathrm{~kg} / \mathrm{da}$ olan konvansiyonel çeşitlere nazaran $660 \mathrm{~kg} / \mathrm{da}$ verim veren ticari hibritler toplam üretim artısında önemli rol oynamaktadır (Yuan 1998). Filipinlerde, 1994 yılında ilk ticari hibrit çeşidi IR64616H, Magat hibrit çeltik çeşidi adıyla piyasaya çıkmıştır. Bu çeşit \%16.4-26.9 arasında heterosis göstermektedir. Yüksek verimli kendine döllenen çeşitlere nazaran hibritlerin en az \%15 daha verimli olduğu hesaplanmıştır (Leon et al. 1996). Vietnam'da Makong ve Red River deltalarında hibrit çeşitlerin konvansiyonel çeşitlere nazaran \%1540 daha verimli olduğu tespit edilmiş ve en verimli konvansiyonel çeşitlere nazaran ortalama \%20 daha verimli olduğu bildirilmiştir (Luat et al. 1996).

Çeltik verimini artırmak için kullanılan yöntemlerden bir tanesi hibrit çeltiklerdir. Hibrit çeltik iki farklı ebeveynin melezlenmesinden elde edilen ve ticari olarak kullanılabilen $F_{1}$ tohumlarıdır. İyi bir hibrit, konvansiyonel tohumlardan (kendilenmiş hatlardan elde edilen çeşitlerden) \%15-20 fazla verim verebilmelidir (Anonim 1997). Çeltik kendine döllenen bir bitki olduğu için ticari olarak hibritlerin kullanılabilmesi için erkek kısır hatların var olması elzemdir. Erkek kısır hatlar izole edilmiş alanlarda tozlayıcılar ile tozlanarak fertil tohumlar üretebilir. Genetik ve genetik olmayan erkek kısırlık sistemleri mevcuttur. Bunlar, sitoplazmik genetik erkek kısırlık (CMS), çevreye duyarlı genetik erkek kısırlık (EGMS), kimyasal erkek kısırlıktır (gametosit, CHA) (Anonim 1997).

Hibrit çeltiklerde hetorosis sayesinde verim artışı sağlandığı kanıtlanmıştır. Ticari hibritler, sitoplazmik erkek kısır (CMS) çeltiğin keşfedildiği Çin'de \%50'den fazla, Amerika'da $\% 15$ 'den fazla ekim alanına ulaşmış ve giderek yaygınlaşmaktadır. Ülkemizde ekim alanı bulunmamakla beraber deneme amaçlı introdüksiyon yoluyla yurt dışından getirilen hibrit çeşitlerin birçoğu iklim şartlarına adapte olamamıştır. Ülke ekolojisine uygun hibrit çeşitlerin geliştirilmesi için ülkesel hibrit çeltik ıslah programının başlatılması gerekmektedir.

Hibrit çeşit geliştirilmesinde ilk aşama erkek kısır hatların geliştirilmesidir. Geliştirilen erkek kısır hatların bazı şartları bulundurması gerekmektedir. TGMS hatların yetiştirildiği ekolojide yüksek oranda steriliteye sahip olması; Gametosit erkek kısırlıkta toksik etki göstermemesi; CMS erkek kısırlıkta farklı ekolojilerde stabil erkek kısır olması, kolay restore edilebilir olması, yüksek tohum verimi için fazla miktarda yabancı toz kabul etmesi, yüksek kombinasyon kabiliyeti, yüksek tane kalitesi olarak sıralanabilir (Anonim 1997).

Bu çalışmada ticari hibrit çeltik oluşturmak amacıyla ana ebeveyn olarak kullanılabilecek erkek kısırlık mekanizmaları üzerinde durulmuştur. Türkiye şartlarında stoplazmik erkek kısırıı (CMS), termogenik erkek kısırıı (TGMS) ve kimyasal erkek kısırlık (gametositler, CHA: Chemical hibridizing agents) sistemlerinden hangisinin uygun olarak kullanılabileceği araştırılmıştır.

\section{Materyal ve Yöntem}

Deneme 2013-2014 yıllarında Trakya Tarımsal Araştırma Enstitüsü deneme arazisinde $\left(41^{\circ} 38^{\prime} 41^{\prime \prime} \mathrm{N}, 26^{\circ} 35^{\prime} 46^{\prime \prime} \mathrm{E}\right)$, iki yıl süreyle yürütülmüştür. Materyal olarak CMS sistemi için, V20A, 15A, 31A ve IR58025A çeşitleri, TGMS sistemi için TGMS1 ve TGMS2 isimli genotipler, CHA sistemi için Paşalı, Halilbey ve Osmancık-97 çeltik çeşitleri kullanılmıştır. Kimyasal erkek Kısırlık için (CHA) 1000 ppm GA3, Salisilik Asit ve Ethephon (Ethrel) hormonları kullanılmıştır, gametositler GS41 (booting stage, sapa kalkma, gebeleşme) döneminde uygulanmıştır .CMS, TGMS ve CHA erkek kısırlık sistemleri için 3 ayrı deneme yürütülmüştür. Denemeler tesadüf blokları deneme desenine göre 3 tekerrürlü olarak kurulmuştur. CMS için zafr izolasyonu, TGMS için perde izolasyonu ve CHA için mesafe izolasyonu kullanılmıştır.

Boş tane, dolu tane, salkım sterilitesi ölçümleri alınmıştır. Sterilite boş tane sayısının toplam tane sayısına bölünerek, \% 'de olarak hesap edilmiştir. Sterilite (\%) =Boş Tane Sayısı×100/(Boş Tane Sayısı+Dolu Tane Sayısı) formülü ile hesaplanmıştır (TTSM 2003). Veriler JUMP istatistik programında analiz edilmiştir ve varyans analizi yapılarak değerlendirilen verilerin ortalamalarının karşılaştırılmasında LSD çoklu karşılaştırma testi uygulanmıştır (SAS 1992).

Uluslararası Çeltik Araştırma Enstitüsünün (IRRI) yayınlamış olduğu Çeltik İçin Standart Değerlendirme Sisteminde (SES) hibrit çeltikler için Erkek Kısır Hatların Erkek Kısırlık Derecelerine göre sınıflandırma yapılmıştır. Buna göre Salkım Sterilitesi \%100 : Tamamen Kısır (1); \%99.0-99.9: Yüksek Derecede Kısır (3); \%95.0-98.9: Kısır (5); \%75.0-94.9 Kısmen Kısır (7); \%70'den az: Fertil yada Kısmen Fertil (9) (IRRI, 2014). 


\section{Bulgular ve Tartışma}

\section{Kimyasal Erkek Kısırlık (CHA)}

Paşalı, Halilbey ve Osmancık-97 çeşitlerine 1000 ppm Giberallik Asit, 1000 ppm Salisilik Asit, 1000 ppm Ethephon uygulaması ve gametosit uygulanmayan kontrol parseli olmak üzere 4 konu üzerinde çalışıımıştır.

İki yılın ortalaması değerlendirildiğinde sterilite değerleri \%8.73-38.33 arasında gerçekleşmiştir (Çizelge 1). Gametosit uygulamalarına bakıldığında salisilik asit uygulaması steriliteyi en fazla artıran uygulama olmuştur. GA3 ve Ethephon uygulaması aynı grupta yer alırken birbirine çok yakın değerler göstermiştir. Kontrol uygulaması ise en az sterilite verirken salisilik uygulamasına göre 4 kat daha az steril bulunmuştur.

Çizelge 1. Gametosit uygulaması sterilite sonuçları (\%) Table 1. Panicle sterility of gametocid application

\begin{tabular}{lcc}
\hline Gametosit & Salkım Sterilitesi & İstatistik Grup ${ }^{* *}$ \\
\hline Salisilik Asit & 38.33 & $\mathrm{~A}$ \\
$\mathrm{GA}_{3}$ & 29.95 & $\mathrm{~B}$ \\
Ethephon & 29.84 & $\mathrm{~B}$ \\
Kontrol & 8.73 & $\mathrm{C}$ \\
\hline
\end{tabular}

Aynı harflerle gösterilen değerler arasında ${ }^{* *} P<0.01$ ve ${ }^{*} \mathrm{P}<0.05$ olasılıkla fark yoktur. $\mathrm{LSD}=0.09 ; \mathrm{CV}(\%)=18.5$ There are no significant differences at ${ }^{* *} P<0.01$ and * $P<0.05$ levels between values followed by same letter

Çeşitler değerlendirildiğinde steriliteler \%22.70-33.83 arasında dağılım göstermiştir (Çizelge 2). Paşalı çeşidi en fazla steriliteyi verirken, Osmancık-97 ve Halilbey çeşidi aynı istatistik grubunda yer almıştır.

Çizelge 2. Çeşitlerin farklı gametosit uygulaması ve kontrol uygulması sonucu oluşan ortalama sterilite değerleri (\%)

Table 2. Average sterility (\%) of varieties with gametocide and control applications

\begin{tabular}{lcc}
\hline Çeşit & Salkım Sterilitesi & İstatistik Grup ${ }^{* *}$ \\
\hline Paşalı & 33.83 & $\mathrm{~A}$ \\
Osmancık & 23.60 & $\mathrm{~B}$ \\
Halilbey & 22.70 & $\mathrm{~B}$ \\
\hline
\end{tabular}

Aynı harflerle gösterilen değerler arasında ** $P<0.01$ ve ${ }^{*} \mathrm{P}<0.05$ olasılıkla fark yoktur. $\mathrm{LSD}=0.09$; CV $(\%)=18.5$ There are no significant differences at ${ }^{* *} P<0.01$ and * $P<0.05$ levels between values followed by same letter.

Çeşit×Gametosit değerlendirildiğinde veriler \%8.23-48.78 arasında dağılım göstermiştir (Çizelge 3). Paşalı çeşidi×Salisilik asit uygulaması $\% 48.78$ ile en yüksek sterilite değerini verirken aynı çeşidin kontrol uygulaması \%8.81 ile en düşük istatistik grubunda yer almıştır. Osmancık$97 \times$ Salisilik Asit uygulaması \%32.41 sterilite değerleri verirken kontrol uygulaması \%8.23 ile en düşük steriliteyi vermiştir. Halilbey çeşidi×Salisilik asit uygulaması $\% 33.80$ sterilite yüzdesi verirken kontrol parselinde $\% 9.14$ değer almıştır.

İki deneme yılında sterilite farkı oluşmuştur. 2014 yılında \%35.6 sterilite değeri verirken 2013 yılında \%17.81 sterilite değeri vermiştir (Çizelge 4). Sterilte farkı yıllara arsası iklim farklııklarında kaynaklanmaktadır. 2013 yılı

Çizelge 3. Çeşit $\times$ Gametosit interaksiyonu salkım sterilite değerleri (\%)

Table 3. Variety $x$ gametocide interaction on panicle sterility (\%)

\begin{tabular}{|c|c|c|c|c|}
\hline Çeşit & Ethephon & GA3 & Salisilik A & Kontrol \\
\hline Halilbey & $26.00 \mathrm{~cd}^{* *}$ & $21.87 \mathrm{~d}$ & $33.80 \mathrm{bc}$ & $9.14 \mathrm{e}$ \\
\hline Osmancık & $24.81 \mathrm{~cd}$ & $28.94 \mathrm{bd}$ & $32.41 \mathrm{bd}$ & $8.23 \mathrm{e}$ \\
\hline Paşalı & $38.70 \mathrm{ab}$ & $39.03 a b$ & $48.78 \mathrm{a}$ & $8.81 \mathrm{e}$ \\
\hline $\begin{array}{l}{ }^{*} P<0.05 \text { ol } \\
\text { There are } \\
P<0.05 \text { leve }\end{array}$ & Ilıkla fark & les follo & $0.16 ;$ & $\begin{array}{l}(\%)=18 \\
01 \text { and } \\
\text { letter. }\end{array}$ \\
\hline
\end{tabular}

iklim değerleri çeltik için uygun bir yıl iken 2014 yılı ilk gelişim dönemlerinde ve çiçeklenme döneminde soğuk stresi oluşturmuştur. 2014 yılında sterilite değerleri artarken verim değerleri de azalmıştır.

\section{Termogenik Erkek Kısırlık (TGMS)}

TGMS1 ve TGMS2 kod numaralı hatlar 2013 ve 2014 yılları yetiştirme sezonunda 3 tekerrürlü olarak araziye ekilmiş ve hasat

Çizelge 4. Çeşit $\times$ Gametosit interaksiyonu salkım sterilite değerleri (\%)

Table 4. Variety $x$ gametocide interaction on panicle sterility (\%)

\begin{tabular}{ccc}
\hline $\begin{array}{c}\text { Deneme } \\
\text { Yılı }\end{array}$ & $\begin{array}{c}\text { Salkım } \\
\text { Sterilitesi }\end{array}$ & $\begin{array}{c}\text { İstatistik } \\
\text { Grup** }\end{array}$ \\
\hline 2014 & 35.6 & $\mathrm{~A}$ \\
2013 & 17.81 & $\mathrm{~B}$ \\
\hline
\end{tabular}

Aynı harflerle gösterilen değerler arasında ** $P<0.01$ ve ${ }^{*} \mathrm{P}<0.05$ olasılıkla fark yoktur. LSD $=0.07$; CV $(\%)=18.5$ There are no significant differences at ** $P<0.01$ and * $P<0.05$ levels between values followed by same letter.

döneminde tesadüfi olarak her parselden seçilen 20'şer salkımın taneleri sayılarak steriliteleri belirlenmiştir. Diğer çeşitlerden toz almamaları için izolasyon perdeleri kullanılmıştır. TGMS çeşitler genel olarak $24 / 30^{\circ} \mathrm{C}$ gece/gündüz sıcaklık derecelerinin 
üzerinde steril olarak tespit edilirken, $16 / 24^{\circ} \mathrm{C}$ gece gündüz sıcaklık derecelerinde kısmen steril olarak tespit edilmiştir (Virmani et al. 2003). Diğer bir deyişle minimum $24^{\circ} \mathrm{C}$ 'nin altında termogenik hatlar fertil olmaya başlamaktadır, $16^{\circ} \mathrm{C}$ 'nin altında ise fertilite değerleri önemli oranda artmaktadır. 2013 ve 2014 yetiştirme sezonunda minimum sıcaklıklar $6.8-16.8^{\circ} \mathrm{C}$ olarak gerçekleşmiştir.

2013 yılında sterilite $\% 90.5$ olarak gerçekleşirken, 2014 yılında \%94.2 olarak gerçekleşmiştir (Çizelge 5). Bir çeşidin hibrit çeltik yetiştiriciliği için TGMS olarak kullanılabilmesi için \%100'e yakın steril olması gerekmektedir.

TGMS1 hattı \%93.0 sterilite değeri verirken, TGMS2 hattı \%91.7 sterilite değeri vermiştir (Çizelge 6). Çeşitler arasında sterilite yönünden istatistiksel önemli bir fark tespit edilmemiştir.

Çizelge 5. İki farklı deneme yılında sterilite değerleri (\%)

Table 5. Sterility (\%) in two successive years of experiments

\begin{tabular}{ccc}
\hline Deneme Yılı & Salkım Sterilitesi & İstatistik Grup \\
\hline 2014 & 94.2 & ÖD \\
2013 & 90.5 & ÖD \\
\hline
\end{tabular}

TGMS1 hattının yaprak ve salkım yapısının dik formda olduğu, yaprağın yeşil rengini olum dönemine kadar koruduğu ve bitki boyunun 80 $85 \mathrm{~cm}$ olarak gerçekleştiği tespit edilmiştir. TGMS2 hattının bitki boyu $80-85 \mathrm{~cm}$ olarak ölçülmüştür.

Her iki hattında erkek kısırlık derecesi IRRI (2014)'ye göre değerlendirildiğinde Kısmen Kısır (5) olarak belirlenmiştir. Değerlendirme metoduna göre 1 ve 3 skala değeri alanlar stabil olarak erkek kısır kabul edilirken diğerleri stabil olmayan erkek kısırlık olarak Çizelge 6. TGMS çeşitlerin salkım sterilite değerleri (\%)

Table 6. Panicle sterility (\%) of TGMS varieties

\begin{tabular}{ccc}
\hline Çeşit & Salkım Sterilite & İstatistik Grup \\
\hline TGMS-1 & 93.0 & ÖD \\
TGMS-2 & 91.7 & ÖD \\
\hline
\end{tabular}

ÖD: İstatistiksel olarak fark yoktur; CV (\% ) $=5.4$ ÖD: Statistically non significant

değerlendirilmektedir. Kullanılan TGMS hatlar Edirne koşullarında Kısmen Kısır ve stabil olmayan erkek kısır hatlar olarak değerlendirilmiştir.

\section{Stoplazmik Erkek Kısırlık (CMS)}

CMS çeşitler V20A, 15A, 31A ve IR58025A çeşitleri 3 tekerrürlü olarak arazi şartlarında ekilmiştir. Çeşitlerin diğer bitkilerden toz almasını önlemek için izolasyon perdeleri kullanılmıştır. CMS çeşitlerin maintainer V20B, $15 \mathrm{~B}$ ve $31 \mathrm{~B}$ çeşitleri yetiştirme döneminde vejetasyonunu tamamlamış ve tohum bağlamıştır ve IR58025A CMS çeşidinin devam ettirici (sürdürücü, maintainer) IR58025B çeşidi vejetasyon döneminde tohum bağlamadığından bölge ekolojisine uygun olmadığı tespit edilmiş ve değerlendirmeye alınmamıştır.

V20A, 15A ve 31A çeşitleri $\% 100$ steril olarak tespit edilmiş ve Edirne lokasyonu ticari hibrit çeltik için kullanılabilir bulunmuştur.

\section{Sonuç}

2013-2014 yılları arasında yapılan bu çalışmada 3 farklı erkek kısırlık metodu Edirne bölgesinde denenmiştir. Gametosit uygulanarak kimyasal erkek kısırlık metodunda yerli çeşitler kullanılmış ve uygulanan dozdaki gamestositlerden en yüksek salkım sterlitesini \%38.33 ile Salisilik Asit oluşturmuştur. Uygulanan gametositlerin fitotoksite oluşturduğu gözlenmiştir. Farklı uygulama dozları, farklı gametositler ve diğer çeşitlerle daha ayrıntılı çalışımasının faydalı olacağı düşünülmektedir.

Termogenik erkek kısırlık (TGMS) sistemi için kullanılan çeşitler TGMS1 ve TGMS2 genotipleri sırasıyla \%91.7-93.0 sterilite değerleri sağlamıştır. IRRI (2014) değerlendirme sistemine göre bu oranlar Kısmen Kısır (5) derecesinde olup hibrit ıslahında kullanılma minimum değeri olan $\% 99 ' d a n$ daha azdır. Sonuçlar, TGMS1 ve TGMS3 hattıyla yapılan çalışmada $22 / 20^{\circ} \mathrm{C}$ gündüz/gece sıcaklıklarında sırasıyla $\% 92.3$ ve $\% 96.3$ sterilite değerleri tespit eden Wongpatsa ve ark. (2014) ile benzer sonuç göstermiştir. Luong ve Qui (1995) yaptıkları çalışmada TGMS1 ve TGMS3 genotiplerinde kısırlık sağlayan genlerin aynı genler olduğunu bildirmiştir. TGMS çeşitler için minimum sıcaklığı $24^{\circ} \mathrm{C}$ 'nin üzerinde olması istenmektedir. Her iki deneme yılı incelendiğinde Edirne için minimum sıcaklıklar $6.8-16.8^{\circ} \mathrm{C}$ ve ortalama sıcaklıklar $18.6-27.0^{\circ} \mathrm{C}$ arasında değişmektedir. TGMS çalışmaları için ortalama sıcaklıkları $27.2-32.0^{\circ} \mathrm{C}$ olan ve çeltik tarımı yapılan Diyarbakır gibi sıcak yörelerde ayrıntılı olarak çalışılmasında fayda görülmektedir. Bunun yanında TGMS çeşitler ile 
kimyasal kısırlığın beraber uygulandığı denemeler yapılabilir. Gün uzunluğuna duyarlı çeşitler bu çalışmada yer almamıştır, çevreye duyarlı genetik erkek kısırlık sağlayan Fotoperiyoda Duyarlı Erkek Kısır çeşitler ile hibrit çalışmaları için erkek kısırlığın uygulanabilirliği Türkiye şartlarında denenmesi uygun olacaktır.

Kullanılan 4 CMS erkek kısır çeşitlerden biri ekolojiye uygun bulunmazken üçü ekolojiye uyum sağlamış ve istenen özelliği taşıyacak şekilde \%100 kısır olarak belirlenmiştir. Sonuçlar değerlendirildiğinde kullanılan dozdaki gametositlerin ve TGMS hatların yeterli düzeyde erkek kısırlık oluşturmadığı; CMS çeşitlerin \%100 kısır olduğu ve Edirne ekolojisinde hibrit çeşit geliştirmek için erkek kısır olarak kullanılabileceği tespit edilmiştir. Bunun yanında farklı gametositler ve farklı dozları, Fotoperyoda duyarlı erkek kısırlık (PGMS) gibi farklı erkek kısırlık sistemleri ve farklı sistemlerinin kombine edildiği çalışmalara ihtiyaç duyulmaktadır.

\section{Kaynaklar}

Anonim, 1997. Hybrid Rice Breeding Manual. International Rice Research Institute Los Baños, Laguna, Philippines

IRRI, 2014. Standard Evaluation System for Rice (SES). International Rice Research Institute. Los Baños, Laguna, Philippines

Leon D.J.D., Redoña E.D., Cruz I.D.D., Ablaza M.F., Malabanan F.M., Lara R.J. and Obien S.R., 1996. Hybrid rice in the Philippines: progress and prospects. Proceedings of the $3^{\text {rd }}$ International Symposium on Hybrid Rice 1416 November 1996 Hyderabad, India. (Advances in Hybrid Rice Technology in IRRI)
Luat N.V., Minh H.T. and Suan N.V.V., 1996. Hybrid Rice Research in Vietnam. Hybrid Rice Technology: New Developments and Future Prospects. Selected Papers from the International Rice Research Conference. International Rice Research Institute, P.O. Box 933, Manila 1099, Philippines

Luong P.N. and Qui T.D., 1995. Preliminary Results of Two Line Hybrid Rice Research. Annual report 1995 of institute of agricultural genetic

Rothschild G.H., 1998. Foreword of Hybrid Rice Breeding Manual. International Rice Research Institute Los Baños, Laguna, Philippines

SAS, 1992. SAS Institute, User's Guide: Statistics, $4^{\text {th }}$ ed. SAS Institute, Cary, NC, USA

TTSM, 2003. Tarımsal Değerleri Ölçme Denemeleri Teknik Talimatı. Çeltik (Oryza sativa L.) Tarım ve Köyişleri Bakanlığı Koruma ve Kontrol Genel Müdürlüğü. Tohumluk Tescil ve Sertifikasyon Merkezi Müdürlüğü Ankara

Wongpatsa U., Kaveeta L., Sriwongchai T., Khamsuk O, 2014. Effect on temperature on male sterility of two Inbred linesof hybride rice. Kasetsart J. (Nat. Sci.), 48: 525-533

Virmani S.S., Sun Z.X., Mou T.M., Jauhar A.A. and Mao X.C., 2003. Two Line Hybride Rice Breeding Manual. Los Banos, Philippinnes. IRRI, 88: 30-56

Yuan L.P., 1998. Hybrid Rice Breeding in China. Advanced Hybrid Rice Teechnology. Chapter 3. Internatinal Rice Research Institute, Philippines 